Article

\title{
Criminal Legislative Policy in the Protection of Water Re- sources with Regard to International Treaties: A case for Ira- nian Legal System
}

\author{
Nima Norouzi ${ }^{\odot}$, Muhammad Sheikhi ${ }^{*}{ }^{\odot}$, Heshmat-Ullah khanmohammadi ${ }^{\odot}$, Mahmood Jafari ${ }^{\odot}$, Soheila \\ Kalantari ${ }^{\odot}$, Soheila Vaziri Narani ${ }^{\odot}$, Ali Shaebani $\odot$
}

How to cite this paper: Norouzi, N., Sheikhi, M., khanmohammadi, H.U., Jafari, M., Kalantari, S., Vaziri Narani, S., \& Shaebani, A. (2021). Criminal Legislative Policy in the Protection of Water Resources with Regard to International Treaties: A case for Iranian Legal System . Universal Journal of Social Sciences and Humanities, 1(1), 67-79. Retrieved from https://www.scipublications.com/journal/index.php/ujssh/article/view/100

\author{
Law and criminology department, Islamic Azad University, Tehran, Iran \\ *Correspondence: sheikhim438@gmail.com
}

\begin{abstract}
Human life and survival on Earth depend on the exploitation of diverse resources, including water. Improper use of environmental resources will lead to pollution and destruction. As one of the most sensitive areas of the environment to which human life depends, water is exposed to a variety of environmental pollutants. The protection of the health of water resources has created the need for intervention and the use of legal and criminal solutions in organizing their use. Domestic penal policy in the field of legislation, inspired by the provisions of Sharia law, along with local and national considerations for the protection of water resources, has directly and indirectly affected the requirements of accession to international instruments and has enacted regulations on the protection of small water resources.
\end{abstract}

Keywords: Water, Environment, Pollutants, Convention, Legislative Policy.

\section{Introduction}

About seven-sevenths of the earth's surface is covered by water. In addition to being rich in food, water also has huge oil and gas resources[1]. For this reason, this vital resource is increasingly being exploited by humans. Extensive use has caused these resources as a large part of the environment to be exposed to the most diverse and serious environmental damage. With this industry, profound changes have taken place in various economic, social and cultural spheres. With the expansion of industries, there was a great need to exploit the natural resources that are used in the fields of energy supply and raw materials, it was felt that in proportion to increasing demand, the rate of human intervention in the natural environment, including water resources, has increased every year. The penetration of various pollutants into natural environments such as water sources increases. Extensive water resources such as springs, streams and small rivers as sources of drinking water have been exposed to many risks due to the influx of industrial and agricultural wastewater and the entry of solid waste from them. Extensive water resources from the tribes and oceans, which have been important since ancient times in terms of transportation and food reserves, are now exposed to flooding with the advancement of technology and as a result of the discovery of mineral and energy reserves[2, 3].

The sources that have been identified as the cause and source of water pollution are divided into two categories: land-based and ship-based. Among the types of pollutants, oil and petroleum products have a very large role in creating water pollution. Crude oil is composed of a combination of saturated hydrocarbons, aromatics, resin and asphaltene $[4,5]$ which is very dangerous for aquatic organisms and the marine environment and humans and causes damage. Serious illnesses become like cancer [6]. Areas in which oil reserves are present are very limited and specific, and are usually far from the consumer 
markets of most industrialized countries, so every year in significant quantities of these materials, on the way to the consumer markets, the amount It is estimated at 320 million tons [4], enters the water life cycle.

Our country, due to its location in the Persian Gulf oil basin, where most of the world's oil resources are located [7], is facing harmful damages due to the entry of these substances into the biological cycles. In this article, an attempt has been made to review the domestic and international documents to which our country has joined, to review the policies and policies adopted in relation to various types of pollutants, and to ask these two questions.

1. What are the criminal policies of the legislature at the national level in the face of various types of water pollution?

2- What measures have been taken regarding water pollution in the transnational documents to which the Islamic Republic of Iran has acceded? Implications of pollution

In the protection of the aquatic environment, one of the most basic issues that must be determined is the concept and content of pollution. The Iranian legislature, in paragraph A of Article 1 of the Law on the Protection of Navigable Seas and Rivers against Contamination with Petroleum Products, approved on 6/31/2010, discharges or contaminates the discharge or the leakage of oil or oil or oil reservoirs or oil reserves. Has been stated. The disadvantage of the above definitions is that instead of a substantive definition that is comprehensive of the types of pollution, it is sufficient to express some examples of pollution[8].

Among the previous laws, we can mention Article 1 of the Law on the Protection of Marine and River Marziaz Contamination of Petroleum Products, approved on 11/14/1975, in which pollution is also mentioned in some cases, such as oil spills or leaks, or Any oil mixture is defined in the terms covered by this law.

This procedure is sometimes current among the regional documents to which the Government of the Islamic Republic of Iran has acceded. For example, in the Convention on the Protection of the Environment of the Caspian Sea (Tehran Convention adopted in 2003 and Implemented in 2006) concluded between the inland countries of the Caspian Sea, under the heading of the first part (general provisions) in Article Carcasses and examples of such are the criteria for defining the discharge of waste and the contamination of the water subject to the Convention[9].

In terms of content among regional documents, the Kuwait 2 F1 Convention provides a more accurate definition of pollution. According to Article 1: "Marine pollution means the introduction of substances or energy into the marine environment by humans directly or indirectly, which have harmful effects such as damage to damaged resources and danger to human health and obstruction of activities. Marine, such as fishing and damage to quality, in terms of the use of seawater and the reduction of amenities, or the possibility of such risks. This definition is more appropriate in terms of the ways of causing pollution, whether direct or indirect, and also in terms of not paying attention to the intentional or unintentional nature of the pollution in the realization of responsibility, and is more than fair to others. In the definition of Article 4 of the Convention on the Law of the Sea, which was adopted on 10 December 1982 and entered into force on 16 November 1994, it is considered that adaptations have been made. Pursuant to Article 1 (4) of the Convention on Pollution "... the introduction of substances or energy into the environment directly or indirectly by humans, such as riverine tributaries, which may cause serious damage to the environment. And endangers marine life and human health and interferes with marine activities, including fishing and other legitimate uses of the sea, and undermines the quality of marine use and reduces its desirability)[10].

Feuer Bach, the originator of the term criminal policy, defines criminal policy as "the legislative wisdom of the state and the set of repressive methods by which the state demonstrates its reaction against crime" [11]. From this perspective, criminal policy, in a 
limited sense, corresponds to the term "criminal policy" in terms of expressing responsibility. After presenting the definition of each of the schools, in accordance with the principles of thought and practical approaches, they have provided various and different definitions of this term. Among the latter, the definition of death of Delmars Martيz seems more appropriate in terms of comprehensiveness and constraint. According to him, "criminal policy includes a set of methods by which the community body organizes the answers to the criminal phenomenon (crime and deviation)" [12]. From a practical point of view, criminal policy is divided into categories such as legislative, judicial and participatory criminal policy [13].

\section{Legal measures for water protection}

\subsection{Domestic Public Law}

Iran is located in hot and dry regions in terms of climate and has faced various periods of drought and water shortage. This issue has become a ground for measures to be taken in Iran regarding water regulation. Due to the need of many people for water and lack of adequate access to surface water, canals have been built to access water. From a glacial point of view, the process of dehydration has led the legislature to require serious protection of water resources. The Civil Code of 1928 assigned articles to the provisions governing rivers, aqueducts, springs, and their sanctuaries, and in the regulation of these articles, the principles of individual ownership and exploitation or participation in private property were accepted. In particular, special attention has been paid to the harmless rule in the development of materials. Following the Civil Code, the Law on Canals was passed in 1930. This law also emphasizes the same principles of the civil law (principles of personal and non-harmful property) and Article 1 stipulates: The executor well will only be me in terms of ownership of the aqueduct and the executor and for the operations related to the aqueduct, and the owner of the property can build a well around the executor well or lands in the well up to the confines of the well and the executor. Do not be an executor. In permissible lands, the incident takes place around the executor's well or between two other wells[13].

Due to the growing importance of water during a gradual process, the need for increased government intervention in infrastructure such as water was felt. This was accelerated by the law establishing the Irrigation Company of 1943. Pursuant to the said article of the law, for the development and reform of the irrigation affairs of the country, an independent enterprise is established under the supervision of the Ministry of Agriculture called the Independent Irrigation Enterprise. The process of the government's strong presence in the field of water management was accelerated by the passage of the 1963 Law on the Establishment of the Ministry of Water and Electricity. In this law, the issue of protection and protection of the aquatic environment is explicitly mentioned and stated in paragraph 1 of Article 1, one of the main goals of the ministry is to monitor the use of the country's water resources, which in an inaccurate and Categories related to various aspects of the environment, such as water management, can be inferred. In 1966, the law on protection and protection of groundwater resources was approved. Article 1 stipulates that the protection and protection of groundwater resources and reserves and the supervision of all matters related to the Ministry of Energy[14].

With the enactment of the Water Law and the manner in which it was nationalized in 1968, water became public and national property, and the legislature, in its position of protection and protection of water resources, explicitly provided for legal mechanisms for water protection. According to Article 1, all irrigation water in rivers, natural streams, valleys, streams and any other natural route, including surface, groundwater, as well as floods, sewers, sewers, sewers, sewers, sewers, sewers, sewers, sewers, sewers, sewers, sewers Springs, mineral waters and groundwater resources belong to the national treasury and belong to the public, and the Ministry of Water and Electricity is responsible for 
maintaining and exploiting this national wealth and constructing and managing the water resources development facility.

In the seventh chapter, under the title of prevention of pollution of water resources, it was stipulated in Article 55 that water pollution is prohibited and institutions that supply water to municipal, industrial or mineral uses are obliged to submit a water purification and wastewater disposal plan to the Ministry of Water and Wastewater. And the Ministry of Health to prepare and implement. In order to provide an indicator for the detection of polluting actions, the legislature further defines in Article 56 (contamination of water) as "mixing of foreign substances into water to the extent that its physical or chemical or biologically harmful quality is harmful to humans." And be cattle, aquatic and plants, change and then consider foreign materials including petroleum, coal, acid and all kinds of carbon and sewage guilds[15].

Among the other laws that have been approved in the field of water protection, the Law on Protection of the Sea and Border Rivers from Contamination with Petroleum Products approved in 1975. This law on increasing the criminal protection of the waters subject to the law mentioned in Articles 13, 10 and 14, stated the scope of duties and legal responsibilities of polluters.

Pursuant to Article 1, all ships covered by this law will be required to be insured against possible damage due to pollution of the sea while entering the Iranian coast. Ships that are not insured must carry a financial commitment to compensate. The purpose of the legislator in adopting these strategies was to ensure the payment of possible damages from oil pollution in the basins considered by the legislator. Article 13 stipulates that if the violation of the provisions of this law causes any damage to the ports and sea (beaches) or other coastal facilities of Iran or damage to aquatic and natural resources, the court shall Article 14 stipulated that pollution officials were required to pay all costs incurred by the competent authorities or on their orders and by other agents in order to limit and eliminate the effects of pollution.

The process of protecting water resources and protecting them continued after the victory of the Islamic Revolution. According to Article 45 of the Constitution, seas, lakes, rivers, and other public waters, except Anfal and public wealth, are considered and are at the disposal of the Islamic government to act in their public interest. It is also stated in the fiftieth principle that in the Islamic Republic of Iran, environmental protection, in which present and future generations should have a growing social life, is considered a public duty. Irreparable damage to it is prohibited. According to the principles and frameworks set out in the Constitution, the ordinary laws have been approved by the Islamic Consultative Assembly, which is in line with the objectives of the plan. One of these approvals is the Law on Fair Distribution of Water, which was approved in 1982. This law is one of the most progressive laws regarding the regulation of the use of water. Article 6, under the title of the second chapter of "Groundwater", stipulates that the owners and users of wells or aqueducts are responsible for preventing water pollution and are obliged to act in accordance with health regulations, if they have the power to do so. They are obliged to inform the Environmental Protection or Health Organization[16].

Article 46 provides: "Pollution of water is prohibited, the responsibility for preventing and preventing the contamination of water resources is assigned to the Environmental Protection Organization."

Assignment of the mentioned matters to the Environmental Protection Organization means violation of Article 1 of the Water Law and the manner of nationalization approved in 1968, because under this article, the Ministry of Water and Electricity is responsible for water conservation and operation.

In order to prevent water pollution subject to the Law on Fair Distribution of Water, the Council of Ministers, based on the proposal of the Environmental Protection Organization and according to Article 46 of the Law on Fair Distribution of Water, approved bylaws with 22 articles in 1994 . One of the points that has been approved in the by-laws 
but does not comply with the general principles of the rule of proper treatment of pollutants, especially water pollution, is paragraph 13 of Article 1, which has the right to: It is said that the management or management of polluting materials sources such as factories, workshops and other industrial facilities, either on its own, or on behalf of another person or natural or legal person, or is solely responsible. Normally, in such cases, the principle is to anticipate the responsibility of natural and legal persons and even the joint and several liability of individuals, so that none of the perpetrators of pollution, whether in the form of stewardship or causation; They are not relieved of any responsibility for their behavior. In addition, more guarantees were provided for the payment and compensation of certain individuals, both legal and natural[17].

Pursuant to Article 22 of the said By-Laws, if violations of the regulations occur and cause damage to aquatic and natural resources, the court shall, at the request of the Environmental Protection Agency, sentence the authorities to pay and compensate the damages.

In terms of strategic and macro-legal solutions of the country in the field of environmental protection, we will need to adopt solutions in the protection of the natural environment of the country. Note 13 of the single article of the law of the first five-year plan of the Islamic Republic of Iran stipulates that factories and workshops are obliged to spend one per thousand of the sale of their products by recognizing and observing the environmental protection organization. Compensate for pollution and create green space.

In the first part, A (3-6-) Environmental sanitation is defined as one of the tasks of the government. The law of the second five-year plan stipulates in part A (2) (3) that during the implementation of the plan, all economic and social activities must be carried out with environmental considerations in mind, and Note 83 stipulates that in order to Prevention and remediation of water resources by industrial wastewaters and factories in cities and industrial towns, in relation to the creation and operation of water and the organization of subdivisions and network management[18].

In the law of the third five-year plan, in Article 104, in order to reduce the polluting factors of the environment, especially in the natural resources and water resources of the country, the production units are obliged to reduce the expenses incurred for adapting their technical specifications to the environmental standards. Consider biodegradation and pollution reduction as acceptable unit costs. Article 68, paragraph A of the Fourth Plan Law stipulates that the government is obliged to plan protection, restoration, reconstruction of reserves and elimination of pollution, and methods of sustainable exploitation of the country's marine environments until the end of the first year of the fourth economic and cultural development plan. Prepare and implement Iran. In the Fifth Development Plan, also in Article 189 (b), the Environmental Protection Agency is obliged to establish an environmental information system by the end of the fifth year of the Fifth Plan, and in accordance with the provisions of Jim and Dal, Article 193, is obliged to enforce Any industrial and mineral exploitation of water has been strictly prohibited from the second year of the program.

Benefiting from a favorable environment is also one of the priorities in the 20-year vision document.

It is expected by the Iranian society. In 2010, the last legislative policy of the legislator in the Law on Protection of Seas and Rivers capable of Shipping against Contamination of Petroleum Products is reflected in twenty-five articles and ten notes. Article 17 of this law stipulates: Owners, operators and officials of creating pollution subject to this law to compensate all damages caused by pollution and all costs of limiting and eliminating the effects of pollution and environmental monitoring, including the cost of equipment and equipment. Services provided by human agents are jointly and severally liable. Adopting this approach is in line with ensuring the payment of damages to the environment and related facilities[19]. 
According to this new environmental measure, the common and multiple responsibility for the total cost of cleaning is placed on the wrongdoers [20].

The issue of responsibility is one of the most important and challenging areas of environmental law. In this area, we are witnessing the transition from the old doctrines of civil liability to modern systems of responsibility. The old theories were mostly based on the theory of fault, and the main goal of this approach is to return the situation to the previous one and compensate the damaged party [20]. Objections and criticisms of this theory due to the lack of complete protection of the environment; Led to the presentation of new theories. Risk-based civil liability theory is one of these theories. According to this theory, there is no need to prove the fault of the polluter in order to fulfill the responsibility, but as soon as the person engages in an activity that leads to environmental pollution and its destruction, he must be liable for the damage, whether or not. The reflection of this principle in the field of environmental responsibilities led to the formation of the "polluter, payer" principle, in which the wrongdoer must accept all the aspects and consequences of his actions and receive damages.

\subsection{Transnational documents}

Chronologically, the beginning of the period of environmental protection in the international system dates back to half a century ago. The issue of a healthy and appropriate environment has become so important that it has been recognized as one of the examples of human rights from the beginning and has been mentioned in the Stockholm Declaration [16]. The conclusion of three hundred multilateral treaties and about one thousand bilateral treaties [17] and seventy international instruments are proof of this resistance. A significant portion of the documents are devoted to the issue of water protection.

\section{Trans-regional documents}

\subsection{Convention on the Law of the Sea}

The emergence of some disputes between countries over the rights of the exploited powers has led the United Nations Commission of Inquiry to formulate principles for the use of the sea by governments. The actions of this commission led to developments in this field. Finally, on December 10, 1982, the Convention on the Law of the Sea was ratified in 320 articles in seventeen sections and entered into force in 1994. The government of the Islamic Republic of Iran has signed this convention but has not ratified it [18]. The most recent achievement of this convention is the twelfth section, which deals with the commitment of states to the protection of the marine environment. Some of the basic provisions of the Convention on the Law of the Sea include Article 192 (Commitment of States to the protection and preservation of the environment); Article 193 (Rights of States in the Exploitation of Natural Resources); Article 194 (Obligation of states to take the necessary measures to prevent and protect the environment) and Article 195 (non-conversion of pollution from one type to another). In the twelfth chapter, it introduces a comprehensive framework of comprehensive measures for marine pollution control [19].

\subsection{Ship Pollution Prevention Convention (MAPOL1F)}

Contamination from ships can be one of the ways oil or chemicals and sewage enter the water. Oil pollution accounts for $71 \%$ of ship-based marine pollution. The annual rate of oil spill in the oceans is estimated at one million tons of oil discharged in standard oil activities and 200,000 tons of oil released as a result of oil tanker accidents per year [20]. The International Maritime Organization had investigated these pollutions before the Convention on the Law of the Sea.

The mission of this organization is to promote healthy shipping as well as to apply and observe the rules of the environment in the watershed [21]. The organization's efforts 
to develop comprehensive measures on marine pollution caused by oil led to the ratification of the International Convention for the Prevention of Pollution from Ships, known as the Marple; This convention was ratified in 1973 and amended in 1978 and finally entered into force in 1983. Iran has also formally signed and ratified the Convention [22].

The importance of the Convention is linked to its annexes, and the annexes to the Marple Convention deal with a variety of issues, including pollution by oil, toxic liquids, hazardous substances, and wastewater. In clauses 4 and 5 of this convention, the state is required to take appropriate steps to enforce the provisions of domestic law for the implementation of the provisions of the convention. Clause 6 allows Member States to inspect foreign vessels entering the territorial waters of a coastal State. This inspection is to control how hazardous materials are discharged by the ship. Clause 7 emphasizes that the inspection must be efficient in order to avoid undue and inappropriate delays and unnecessary seizures of the ship [23].

\subsection{Convention on Oil Pollution Preparedness and Response (OPRC)}

This Convention is the result of the actions of the International Maritime Organization concerning shipwrecks and maritime emergencies that could lead to marine pollution and widespread environmental degradation. This convention was ratified in 1990 and entered into force in 1995. In 1997, the Government of Iran acceded to the above-mentioned Convention. Increasingly, the national duty to protect the marine environment in the event of an accident has led to oil pollution. The territory covered by this national plan includes the coastal area and all waters under the supervision and rule of the Islamic Republic of Iran in the Persian Gulf region, the Oman Sea and the Caspian Sea. This plan has been ratified in accordance with paragraph 3 (2) of the Convention, which requires members to establish national systems and national plans to respond promptly to accidents leading to oil pollution [21-24].

\subsection{Kuwait Convention Regional Documents}

The Persian Gulf region has been recognized as a semi-partisan sea by the International Maritime Organization and the United Nations Environment Program [25] under the Convention on the Law of the Sea [25]. Article 60 (a) 211 of the Convention on the Law of the Sea, coastal States have the right to determine the specific and sensitive areas of their seas by providing details. In terms of convention; Special areas are points that, for reasons known to be associated with oceanic, ecological, and maritime traffic conditions, as well as due to the utilization and protection of their resources due to the need to avoid special measures in order to prevent them from being prevented. Widespread exploitation of oil tankers and ships is exposed to various types of environmental damage. The countries of Iran, Kuwait, Bahrain, Iraq, Qatar, and the United Arab Emirates ratified the Convention on April 24, 1978, with the aim of cooperating in the protection of marine habitat. It was implemented by the Ministry of Foreign Affairs of Kuwait [26].

Following the ratification of this Convention, other protocols entitled "Protocol" on Marine Pollution from Exploration and Extraction from the Offshore Plateau "Protocol" on the Protection of the Marine Environment from Pollution from Land-Based and Red Crescent Resources. The government of the Islamic Republic of Iran has ratified all of them and only signed the maritime transport protocol.

According to Article 2, the provisions of the Convention do not apply to the inland waters of the members. According to Article 3, one of the key objectives of the Kuwait Convention is to reduce and combat pollution of the marine environment in the region. Pursuant to Article 16, a regional organization for the protection of the marine environment, called Rapmi, has been established for the implementation and implementation of the requirements of the Convention, which is based in Kuwait.

Another center established under the Kuwaiti Convention is the Center for Mutual Cooperation at Sea (MEMAC), based in Bahrain. In addition to the two organizations, due 
to the importance of protecting the marine environment and taking timely action in the event of accidents leading to oil pollution, the necessary cooperation and coordination between the countries of the region in 2003 became the Center for Cooperation in Resolving Oil(ORC). The important task of this center will be to provide related measures to prevent and deal with oil spills at sea through cooperation between states, oil companies, and international competition organizations based on the principles of prudence and clean-up.

\subsection{Tehran Convention}

The Caspian Sea, as the largest lake on earth, has a special environmental importance due to its special ecological location and is almost rectangular in shape [22]. The length of the Caspian Sea coastline is about $7000 \mathrm{~km}$, of which about $1000 \mathrm{~km}$ from Astara to Atrak is one of the coasts of Iran [23-25]. Due to the closure of its aquatic ecosystem, their environment is always exposed to the dangers of environmental pollutants. Among the factors that severely threaten the health of the Caspian Sea are oil pollutants. In the latest assessments, the amount of oil reserves has reached more than 50 million networks [24]. In order to cooperate between the countries of the Caspian Sea basin in the field of environmental issues, on November 4, 2003, in Iran, the Tehran Convention was signed between the governments of Iran, Russia, Kazakhstan, Turkmenistan and Azerbaijan. The text of the Convention mentions eight protocols. One of the protocols is regional cooperation to deal with oil pollution in emergencies. In Article 2, the purpose of the Convention is to protect the environment of the Caspian Sea from all sources of pollution and to protect and maintain, rationally and sustainably use its living resources.

Pursuant to Article 5, the Contracting Parties shall, in order to achieve the objectives of the Convention, adhere to principles such as the precautionary principle, the polluting principle, which is one of the new principles of environmental pollution, and the principle of access to information on environmental pollution. The types of contamination are also specified according to the source (Articles 7, 8, 9, 10 and 11).

\section{Criminal measures}

Human use of punishments to protect the values that are necessary to preserve the core resources of individuals and society dates back to several thousand years ago. However, it should be emphasized that the task of criminal law is not always to acknowledge, strengthen and protect the higher values of society, which are often observed by the people without resorting to punishment. This right can also control behaviors through criminalization and punishment and, as a result, produce values and norms that are valued and observed in accordance with the policies and strategies of the ruling party on social, political and economic issues of the society. [25]. At present, access to a healthy environment has been recognized as one of the collective values in many constitutions of the country. Due to the fact that water resources in terms of size and importance can be divided into two types of limited water resources such as springs and streams and small rivers and large water resources including rivers can be navigable and seas, therefore, in this regard. Related penalties are reviewed.

\subsection{Criminal protection of limited water resources}

In 1968, with the passage of the Water Law and its nationalization, the legislature transferred ownership of water from individuals to the government, and the use and exploitation of water also became subject to new conditions. In the eighth chapter of the law, as offenses and crimes, some measures were criminalized and some punishments such as fines, blocking wells and disciplinary imprisonment were determined (Articles 59, 60, 61). Paragraph 5 of Article 60 stipulates that anyone who intentionally contaminates river water, public rivers, streams, reservoirs, springs, aqueducts and wells by adding foreign matter as provided in Article 56 of the law, in cases where the source of water is water. The perpetrator will be prosecuted under other laws. In this material, water contamination is 
the mixing of foreign substances with water to the extent that its physical, chemical or biological quality is harmful to humans, livestock, aquatic animals and plants. One of the other laws that has taken a criminal approach to the prevention and prevention of pollution, especially water, is; The Law on Environmental Protection and Improvement was approved in 1974. According to Article 1, protection, improvement and improvement of the environment, prevention and prevention of any pollution and any destructive action that causes the balance and appropriateness of the environment to be disturbed, as well as all matters related to the organization's environment, wildlife and conservation of aquatic life. .

Pursuant to Article 11, the Environmental Protection Agency, in compliance with the relevant regulations, identifies the factories and workshops that cause environmental pollution and notifies them in writing to eliminate the defects within a certain period of time. If the persons concerned do not stop the notification of the prohibited work or activity, their continuation of their activity will be subject to the opinion of the court and in case of violation, they will be sentenced to imprisonment for one day to one year or a fine or both.

At a glance, we can deduce the dispersion and incoherence of legislative legislative policies on water pollution. It is clear that one of the secrets of success in criminal legislation is coherence in the enactment of laws, which is not observed in the resolutions, and in some cases the legislature has only passively criminalized some matters. With the enactment of the Law on Fair Distribution of Water in 1982, despite the climatic situation of the country and the growing need for water resources and the growing problems that polluted water has created for the health of human beings [26], only the case mentioned in Article 46 in It is only stipulated that "water pollution is prohibited, the responsibility for preventing and preventing the pollution of water resources is assigned to the Environmental Protection Organization". Unfortunately, this regulation has not improved compared to the previous laws. It should be noted that the legislature has not provided any enforcement guarantees for the actions of individuals who attempt to pollute water resources and has reduced the article to the level of moral advice. This legislative negligence becomes even more pronounced when in Article 45, for persons who seize another's water right without a license, the punishment of restitution and compensation and the punishment of 10 to 50 lashes or 15 days of disciplinary imprisonment Prediction; However, no metaphor has been envisaged for water contaminants [27].

Finally, in the Islamic Penal Code adopted in 1996 on the criminalization of actions that cause environmental pollution in the watershed, we see the adoption of measures much heavier than the previous laws.

Article 688 of the Islamic Penal Code stipulates that any action that is considered a threat to public health, such as contaminating drinking water, or distributing contaminated drinking water, dumping poisonous substances in the river, is considered a major cause of death. They will be sentenced to one year. The diagnosis is made by the Ministry of Health and the Environment Organization. The legislature has enumerated some examples as an allegory, which can be useful in developing examples and similar cases that can be subject to the mentioned punishments.

In Article 689, the legislator has also determined the damages to persons and if the actions mentioned in Article 688 that lead to murder or mutilation or other injuries, as the case may be, are subject to the permissions of the storytellers and the payment of diyat and total payment. He knows the damages. In general, these two substances can be useful in combating pollution caused by limited water resources because they deal with both prevention and punishment and include both stages [27].

\subsection{Criminal protection of large water resources}

This law was approved in 1975 regarding the border rivers and inland waters and lands of Iran in the Oman Sea, the Persian Gulf and the Caspian Sea. According to Article 2 of the said law, contamination of the expressed water with oil or any kind of oil mixture 
by vessels and other oil facilities located on land or at sea is prohibited, and those who commit such crimes will be imprisoned and fined or fined. Two sentences are sentenced. If the contamination is due to negligence or carelessness, the contaminant will be fined. One of the notable points is the conviction of a person to the prescribed penalties in both cases of intentional and unintentional commission, which is one of the salient points considered and in line with the principles governing the determination of responsibility in environmental crimes.

A weakness that is considered in this law and in other environmental laws is the excessive use of imprisonment and fines by the legislature. Nowadays, environmental crimes are often committed by legal entities, so it seems more appropriate to use the legal and professional enforcement of alternatives to imprisonment. Today's criminal policy is, on the one hand, to reject the severity and, in particular, the subordination and deprivation of the criminal rights of convicts in the past, which is generally incompatible, and on the other hand, considering the economy. The circumstances of the offender and the social environment seek to establish a system quite different from prohibitions or restrictions that is capable of supporting both the potential victims of certain economic or professional activities and those of the perpetrators themselves. To support [28].

These punishments are usually complementary and optional, but can be foreseen in some cases as such. [29] Environmental offenses include penalties such as commercial restrictions related to pollution or revocation of licenses, descriptive penalties that reduce the popularity of companies and corporations, and penalties such as those that increase social costs. And the job of these people can be used. Article 6 provides for exceptions to the absolute liability set out in Article 2. According to Article 6, the penalties prescribed in the article, in case the pollution is necessary in order to eliminate the danger from the ship or to save the lives of the persons; Provided that the proportion between the contamination with the hazard threatening the ship or its occupants is observed and immediate measures to eliminate the contamination are unimpeded. In the case of unintentional contamination that has not been predicted as a result of factors and events, immediate measures should be taken to prevent and eliminate its effects.

In Article 12, the officers of the Ports and Maritime Organization will be officers within the limits of their duties, provided that they are assigned by the respective organization and pass special courses for officers, under the supervision of the prosecutor and obtaining a certificate for passing these courses. Pursuant to Article 17, the time of a claim for damages is six years from the date of the claim. This law has been repealed by the Law on the Protection of Navigable Seas and Rivers, which will be examined in the next section.

Law on protection of navigable seas and rivers against pollution by petroleum products:

The mentioned law was approved in 2010. Certainly, the increasing spread of oil pollution in our country's marine basins has been motivated until after 35 years; A law similar to the Law on the Protection of Marine and Border Rivers from Oil Pollution, passed in 1975, should be enacted. The scope of application of both laws is the same and includes the law of Iran's maritime regions in the Persian Gulf and the Sea of Oman. It should be said that in the law mentioned in paragraph 6 of Article 6, the creation of any pollution of the marine environment, contrary to the provisions of the Islamic Republic of Iran, is considered a crime and subject to criminal punishment and civil liability.

Considering that most of the articles in the 2010 law are repetitions of the articles of the previous law, only those articles that are not mentioned in the previous law are analyzed. Article 4 criminalizes the misappropriation and non-performance of legal duties and the registration of false information in the oil registration book by the officials of the ship, tanker, platform and oil facilities in the case of criminalization and imposes fines and fines for it. The crime of falsification and recording of untrue material is in accordance with the criminal titles of forgery of material and provisions in the Islamic Penal Code. 
Therefore, if a person commits these crimes, he will be fined for multiple crimes (spiritualizing an act and violating several laws) and according to the obligation of Article 46 of the Islamic Penal Code, if he has several titles in the punishable crimes of a single act. The punishment is more severe. Pursuant to Article 10, the above-mentioned officials, in case of contamination for any reason, should inform the competent authorities as soon as possible and be sentenced to administrative punishment and fines.

Among other innovations of the law is the provision of performance guarantees for the duties assigned to government officials in order to prevent the spread of infection and to deal with violators, which is a combination of administrative penalties and fines [28]. One of the positive and novel points of the 2010 law is the prediction of a three-member expert board to diagnose and determine the appropriateness of actions with risks, the effectiveness of the actions taken with the materials that have resulted in the risk and the risk of harm and loss. which will play an effective role in making the decisions taken by the relevant authorities more objective.

\section{Conclusions}

The protection and preservation of large and small water resources has been going on for a long time and governments and international organizations due to the growing need for water and its scarcity, population growth and the threshold of high vulnerability of all kinds of water. National, regional and international levels have adopted solutions. In Iran, despite the severity and abundance of environmental hazards that threaten the country's water resources, so far only in some laws, legal and criminal measures have been taken to regulate and protect water resources. Certainly, passing legislation that is inspired by local and global strategies for the protection of the aquatic environment can be very effective. The existence of a specialized and comprehensive law in this regard, certainly in the degree of efficiency and increase the capability of the responsible agencies, in the protection of the above-mentioned objectives and the strengthening of inter-sectoral cooperation, which is one of the requirements of the restrictive watershed. One of the problems in the field of environmental protection is the non-institutionalization of environmental protection, as a fundamental and pivotal value in the relevant and responsible institutions, both legislative and judicial. Resolving this problem requires educational and cultural work at the sixteenth level to explain the position and role of the country's natural resources, especially the aquatic environment.

\section{Supplementary Materials: "Not Applicable."}

Author Contributions: “Conceptualization, S.K. and M.S.; methodology, N.N.; software, M.J.; validation, H.K., S.V. and A.S.; formal analysis, N.N.; investigation, H.K.; resources, N.N.; writingoriginal draft preparation, H.K.; writing - review and editing, M.J.; supervision, N.N.; project administration, M.S. All authors have read and agreed to the published version of the manuscript."

Funding:: "This research received no external funding."

Data Availability Statement: “Not Applicable."

Acknowledgments: “Not Applicable."

Conflicts of Interest: “The authors declare no conflict of interest."

\section{References}

[1] Directive 2007/60/EC of the European Parliament and of the Council of 23 October 2007 on the Assessment and Management of Flood Risks. Available online: https://eur-lex.europa.eu/legal-content/EN/TXT/?uri=CELEX:32007L0060 (accessed on 15 February 2021).

[2] Directive 2000/60/EC of the European Parliament and of the Council of 23 October 2000 Establishing a Framework for Community Action in the Field of Water Policy. Available online: https://eur-lex.europa.eu/legal-content/EN/TXT/?uri=CELEX:32000L0060 (accessed on 15 February 2021). 
[3] Directorate General for the Environment (European Commission). Note by DG Environment. Subject: Towards Better Environmental Options for Flood Risk Management; European Commission: Brussels, Belgium, 2011.

[4] Zevenbergen, C.; Veerbeek, W.; Gersonious, B.; Van Herk, S. Challenges in Urban Flood Management: Travelling across Spatial and Temporal Scales. J. Flood Risk Manag. 2008, 1, 81-88.

[5] Hall, J.W.; Meadowcraft, I.C.; Sayers, P.B.; Bramley, M.E. Integrated Flood Risk Management in England and Wales. Nat. Hazards Rev. 2003, 4, 126-135.

[6] Dadson, S.J.; Hall, J.W.; Murgatroyd, A.; Acreman, M.; Bates, P.; Beven, K.; Heathwaite, L.; Holden, J.; Holman, I.P.; Lane, S.N.; et al. A Restatement of the Natural Science Evidence Concerning Catchment-Based 'Natural' Flood Management in the UK. Proc. R. Soc. A 2017, 473, 20160706. [PubMed]

[7] Seher, W.; Löschner, L. Balancing Upstream-Downstream Interests in Flood Risk Management: Experiences from a CatchmentBased Approach in Austria: Balancing Upstream-Downstream Interests in Flood Risk Management. J. Flood Risk Manag. 2018, $11,56-65$.

[8] Lane, S.N. Natural Flood Management. Wires Water 2017, 4, e1211.

[9] Directorate General for the Environment (European Commission). EU Policy Document on Natural Water Retention Measures: By the Drafting Team of the WFD CIS Working Group Programme of Measures (WG PoM); Publications Office: Luxembourg, 2014.

[10] Vis, M.; Klijn, F.; De Bruijn, K.M.; Van Buuren, M. Resilience Strategies for Flood Risk Management in the Netherlands. Int. J. River Basin Manag. 2003, 1, 33-40.

[11] Wingfield, T.; Macdonald, N.; Peters, K.; Spees, J.; Potter, K. Natural Flood Management: Beyond the Evidence Debate. Area 2019, 51, 743-751.

[12] Kenyon, W.; Hill, G.; Shannon, P. Scoping the Role of Agriculture in Sustainable Flood Management. Land Use Policy 2008, 25, 351-360.

[13] Stürck, J.; Poortinga, A.; Verburg, P.H. Mapping Ecosystem Services: The Supply and Demand of Flood Regulation Services in Europe. Ecol. Indic. 2014, 38, 198-211.

[14] Carter, J.G.; Handley, J.; Butlin, T.; Gill, S. Adapting Cities to Climate Change-Exploring the Flood Risk Management Role of Green Infrastructure Landscapes. J. Environ. Plan. Manag. 2018, 61, 1535-1552.

[15] Calder, I.R.; Aylward, B. Forest and Floods: Moving to an Evidence-Based Approach to Watershed and Integrated Flood Management. Water Int. 2006, 31, 87-99.

[16] Hartmann, T. Contesting Land Policies for Space for Rivers-Rational, Viable, and Clumsy Floodplain Management. J. Flood Risk Manag. 2011, 4, 165-175.

[17] Fournier, M.; Larrue, C.; Alexander, M.; Hegger, D.; Bakker, M.; Pettersson, M.; Crabbé, A.; Mees, H.; Chorynski, A. Flood Risk Mitigation in Europe: How Far Away Are We from the Aspired Forms of Adaptive Governance? Ecol. Soc. 2016, 21 , art49.

[18] Schanze, J. Nature-Based Solutions in Flood Risk Management-Buzzword or Innovation? J. Flood Risk Manag. 2017, 10, 281282.

[19] de Jong, C. European perspectives on forest hydrology. In Forest Hydrology: Processes, Management and Assessment; Amatya, D.M., Williams, T.M., Bren, L., de Jong, C., Eds.; CABI: Wallingford, NY, USA, 2016; pp. 69-87. ISBN 978-1-78064-660-2.

[20] Zal, N.; Bastrup-Birk, A.; Bariamis, G.; Scholz, M.; Tekidou, A.; Kasperidus, H.D.; Baltas, E.; Mimikou, M. Water-Retention Potential of Europe's Forests: A European Overview to Support Natural Water-Retention Measures; EEA Technical Report; Publications Office of the European Union: Luxembourg, 2015; ISBN 978-92-9213-694-9.

[21] Tzioutzios, C.; Kastridis, A. Multi-Criteria Evaluation (MCE) Method for the Management of Woodland Plantations in Floodplain Areas. ISPRS Int. J. Geo. Inf. 2020, 9, 725.

[22] Hartmann, T.; Spit, T. Legitimizing Differentiated Flood Protection Levels - Consequences of the European Flood Risk Management Plan. Environ. Sci. Policy 2016, 55, 361-367.

[23] Vinke-de Kruijf, J.; Kuks, S.M.M.; Augustijn, D.C.M. Governance in Support of Integrated Flood Risk Management? The Case of Romania. Environ. Dev. 2015, 16, 104-118.

[24] Lindahl, T.; Söderqvist, T. Building a Catchment-Based Environmental Programme: A Stakeholder Analysis of Wetland Creation in Scania, Sweden. Reg. Environ. Chang. 2004, 4.

[25] Machac, J.; Hartmann, T.; Jilkova, J. Negotiating Land for Flood Risk Management: Upstream-Downstream in the Light of Economic Game Theory. J. Flood Risk Manag. 2018, 11, 66-75.

[26] Lee, F.; Moss, T. Spatial Fit and Water Politics: Managing Asymmetries in the Dongjiang River Basin. Int. J. River Basin Manag. 2014, 12, 329-339.

[27] Parrot, A.; Brooks, W.; Harmar, O.; Pygott, K. Role of Rural Land Use Management in Flood and Coastal Risk Management. J. Flood Risk Manag. 2009, 2, 272-284.

[28] Albrecht, J. Legal Framework and Criteria for Effectively Coordinating Public Participation under the Floods Directive and Water Framework Directive: European Requirements and German Transposition. Environ. Sci. Policy 2016, 55, 368-375.

[29] Gersonious, B.; van Buuren, A.; Zethof, M.; Kelder, E. Resilient Flood Risk Strategies: Institutional Preconditions for Implementation. Ecol. Soc. 2016, 21, art28. 
[30] Spray, C.; Ball, T.; Rouillard, J.J. Bridging the Water Law, Policy, Science Interface: Flood Risk Management in Scotland. J. Water Law 2009, 20, 165-174. Author 1, A.; Author 2, B. Title of the chapter. In Book Title, 2nd ed.; Editor 1, A., Editor 2, B., Eds.; Publisher: Publisher Location, Country, 2020; Volume 5, pp. 154-196. 